\title{
Institutional Digital Repositories in Nigerian: Issues and Challenges
}

\author{
Musa, Aminu Umar; Shittu Musa, and Abdulkadir Aliyu \\ (B.L.I.S) Assistant Librarian Kashim Ibrahim Library Ahmadu Bello University, Zaria Kaduna State, Nigeria \\ (B.L.I.S) Assistant Librarian Faculty of Social Science Librarian Ahmadu Bello University, Zaria Kaduna State, \\ Nigeria
}

(B.L.I.S., M.L.S) Librarian II Kashim Ibrahim Library Ahmadu Bello University, Zaria Kaduna State, Nigeria

\begin{abstract}
This paper explores the historical development, current practices and the challenges affecting the institutional digital repositories in Nigeria; it identifies the various universities that establish digital repositories. The paper further highlight the prospect of Nigerian University Libraries in the implementing institutional digital repositories as it holds great promise for preservation of materials, sharing of resources, and visibility of Nigerian libraries and institutions across the globe. The increase in Nigerian content on the Web will enable more meaningful and fruitful researches to be conducted through access to relevant data and literature. The study discovers finance, copyright issues, epileptic power supply, difficulty in digitizing some materials, technical support and security; constant change of hardware and software are among the challenges facing the digitization project and institutional repositories respectively. The research concludes that digitization of library resources in the 21st Century can revitalized the libraries as information provider.
\end{abstract}

\section{Introduction}

Libraries were among the early users of information technologies to manage their operations as per back as 1930s and have continued to adapt albeit slowly to changing technological environment characterized by emerging new technologies and applications and issues of globalization. More than ever before, libraries are facing tremendous challenges in meeting the evolving and sophisticated needs of a diversity of users. Increasingly, the global environment characterized by concerns about globalizations issues such as, digital divide, information society, and attainment of millennium development goals necessitate participation of libraries as key information providers to collaborate with governments, development agencies, NGOs, academia, and private sector to address these issues.

In the $21^{\text {st }}$ Century, universities libraries in Nigeria have embarked on integration of technology in their operations. This serves as a mechanism for improvement and development, especially, in a situation where attention is drawn to the academic contents and ways of digitizing and preserving them for future use. Libraries have long played an essential role in containing, preserving, and sharing of information. Many information technologies have been created over the years; to cater for the entire library operations, particularly information storage and retrieval. University libraries are fully involved in this development as they are the heart of the University, being that they house the intellectual resources of the institutions. The effort to digitize the intellectual property of the institution is what is known as digitization (Eke, 2011).

Part of the emerging role of academic libraries is the implementation of institutional repositories (IRs), digital collections that capture and preserve the intellectual output of university communities (Crow, 2002).According to eHow Institutional Repository started with the advent of the World Wide Web (WWW). In 1991 the e-print service arXiv was developed by Los Alamos physicist Paul Ginsparg. It eventually led to the Open Archive Initiative in which it enables institutional repositories to operate together. In 2001 Eprints was developed, while 2002 Dspace and HP and in that same year FEDORA (Flexible Extensible Digital Object Repository Architecture) was developed. This software is used as platform to deploy IRs. They are the programmes that provide structured data-entry points for digital resources leading to semantic relationships. Semantic relationships are further enhanced by the introduction of metadata, i.e. data about data, which increases the direct findability of resources, rather than mere accessibility. Find ability of resources is used to denote the aggregation of relevant materials in their order of importance, with synonyms, and with options for different media or format, such as texts, sound, motion, graphics, or any combinations of these (Akintunde and Anjo, 2012).

Various authors have defined Institutional Repositories (IRs) but the frequently cited definition is that of Lynch (2003), viz. "a set of services that a university offers to the members of its community for the management and dissemination of digital materials created by the institution and its community members. It is most essentially an organizational commitment to the stewardship of these digital materials, including long-term 
preservation where appropriate, as well as organization and access or distribution". Johnson (2002) defines an IR simply, as "a digital archive of the intellectual product created by the faculty, research staff, and students of an institution and accessible to end-users both within and outside of the institution with few if any barriers to access". The essential characteristics of an IR are that it is institutionally defined, scholarly in scope, cumulative and perpetual, open and interoperable (Crow, 2002). Deposit within an IR is carried out in order to maximize the visibility and accessibility of comprehensive, local research. IRs are beneficial to both the researcher and the researcher's institution (Lynch, 2003). An IR sits firmly within the DS landscape, which includes "building digital collections, creating tools for collecting, analyzing, and authoring digital information, and using digital collections and analytical tools to generate new intellectual products" (American Council of Learned Society, 2006). Therefore, IR can also be considered as a benchmark of Digital Scholarship.

In Nigeria, the idea of institutional repositories (IRs) is a current theme in tertiary institutions that have seen it as a necessity for making available their institutional resources, thereby increasing their visibility and better performance in the ongoing web ranking of world universities in particular. In the last three years, Nigerian universities have, more or less, competed among themselves to have higher ranking in the web metrics ranking of world universities. This has been a healthy competition because more and more of the institutions have been devising creative means of increasing their digital contents in the public domain, resulting in more Nigerian content on the Internet, and, particularly, more openness and share-ability of institutional resources (Akintunde and Anjo, 2012).

Therefore this paper highlights the current practices in the area of digitization and institutional repositories in Nigeria, registered with Open Directory of Open Access Repositories (OPENDOAR).The paper suggests that while tertiary institutions and their Libraries are moving ahead to establish repositories in order to maximize the visibility of their academic output, and make it as widely available as possible, there are still considerable encumbrances and hiccups that inhibit academic community from participating in the project.

\section{Institutional Digital Repositories in Nigerian:}

The world is fast changing; academic Institutions are now responding to these global changes by adopting Institutional digital repositories in their various institutions. Florida State University (2012) observed that supporting faculty and researchers by offering greater, more immediate access to peer research will improve the caliber of scholarship that institution produces. Thata (2007) while reporting the digitization exercise at the University of Zimbabwe stated that, the University of Zimbabwe library started participating in (DATAD) in 2002.The Database of African Theses and Dissertations of the Association of African Universities (AAU). Through this facility, titles, abstracts, and the names of authors and supervisors, were uploaded to a database that is searchable on the World Wide Web. A natural growth of this was the development of a full-text e-theses database, the Electronic Theses and Dissertations database (ETD). This is searchable and accessible on the campus-wide network; the library is engaged in discussions with the university community on how to expand access to the e-theses by the wider community beyond the University of Zimbabwe. Some Nigerian universities embarked on similar project of digitizing their local content one of which is Ahmadu Bello University Zaria, where the project started in July 2005, then only title page and abstract were digitized using flatbed scanner the item/content is usually save on Database of African Theses (DATAD). In the year 2008 universities of Jos joint the trends deploying D-space software, later on other universities followed.

\section{Benefit of Setting up Institutional Digital Repository}

However, Cullen and Chawner (2008) postulated that reasons for setting up repositories vary, and a range of projected benefits has been suggested in many literatures. These include benefits to the researcher, to the institution, and to individual disciplines. Academic libraries also benefit from being involved in institutional repository initiatives, and there are implications for scholarly communication overall. The primary reasons used to persuade academics of the benefits of placing their output in an institutional repository is exposure - that by having their research and publications openly available on the Web, not just in fee-based databases, scholarly journals, or books, their work is likely to be used and cited more. As a result, their reputation will be enhanced over the long term, due to the recognition they gain from this (Pinfield, Gardner and MacColl, 2002). Other benefits to researchers include stewardship and preservation of their publications in digital form, which frees them from the need to maintain this content on a personal computer or website (Lynch, 2003).

Many benefits are identified, at the institutional level, or even at the national level. In Japan, for example, the Ministry of Education, Culture, Sports, Science and Technology has encouraged Japanese university libraries to develop institutional repositories to promote sharing of knowledge throughout Japan and internationally (Cullen and Nagata, 2008).

The development of institutional repositories in Africa is seen as a way of making institutional research outputs available to a community with less than optimal access to resources (Musoke, 2008). Akintunde and Anjo (2012) observed that in Nigeria Digitization holds the advantage of providing a platform for sharability 
and duplicity of data, and networking because of the digital form of content. It also enhances the life-span of records as well as securing data and records that would have been obliterated due to their age.

\begin{abstract}
Nigerian Periscope
In Nigeria, Universities have therefore taken up the challenge of automating their libraries, by putting some remarkable effort to source the requisite funds to digitize and archive their library resources for easier web-based access.(Eke,2011). For Kashim Ibrahim library which is the main Library of Ahmadu Bello University, Unesco's sponsorship of the heads of six University librarians to a workshop on the use of the Greenstone open source software, sparked the library's initial interest in digitization. Additionally, digitization of theses and dissertations at the university libraries of Jos and the Obafemi Awolowo University, under the AAU-DATAD programme, provided a model for ABU to start digitizing its post-graduate theses and dissertations. The ultimate aim was to provide global access through the Internet for all the theses and dissertations accepted for higher degrees in the University.

According to Fabunmi, Paris and Fabunmi (2006) library digitization has become part and parcels of librarians and information scientist, and most libraries in Nigeria are involved in digitization. They further opine that as the manual system of searching for information and materials in the traditional library does not permit multiple use of the same material by different library users unlike the online library system. It is inefficient and time consuming, hence the need to exploit the advantages of the digital library which enables a library to provide online services. The institutional repositories in Nigerian Universities will be treated under the following headings:
\end{abstract}

\title{
Ahmadu Bello University
}

According to Musa and Musa (2012) the digitization project in Kashim Ibrahim Library, which is the main library of Ahmadu Bello University, Zaria started with a set target of digitizing Theses, Dissertations, Seminar Papers and Conference Proceedings. The project started in July 2005, by digitizing only title page and abstract at the initial stage using flatbed scanner by saving the information using Database of African Theses and Dissertations (DATAD). As time goes on the Project witnessed a tremendous progress where more scanners were acquired, Xerox DocuMate 752. The use of Xerox DecuMate 752 has greatly transform the digitization exercise, where by full text are now being digitized and uploaded onto D-Space open source self archiving software. This scanner is one of the recent advance version that has the ability to scan multiple pages using the scanner's feeder with the aid of software called ABBYY FineReader 8.0 Professional Edition, even though; there is an upgrade of this version of software which is called version 11. Part of the policy of the project is that only materials from the year 2000 downward should be scan in hard copy while from 2000 upward the soft copies are to be converted in to portable document file (PDF), which will then be directly, uploaded using D-Space. The repository can be access through the following link http://kubanni.abu.edu.ng:8080/jspui

\section{University of Jos}

The University of Jos library, in June 2009 became the first institution in Nigeria to establish an Institutional Repository (IR) (Akintunde, 2010), and the second in West Africa after the University of Science \& Technology, Ghana. The library uses Dspace, open source self archiving software. This was not the university's first experience in the use of open source solutions. The university uses Moodle (www.unijos.edu.ng/moodle) to deliver electronic learning. The website of the university is managed using Drupal, an open source content management system. In 2003, the University of Jos, along with seven other universities in Africa, were the founding members of African Virtual Open Initiatives \& Resources(AVOIR) which was a novel network for capacity building in network engineering developing free and open source software to facilitate electronic learning and business transactions across Africa as a first step (Keats, 2006, 2010). AVOIR developed and deployed Knowledge Environment for Web based Learning (KEWL) which was used to deliver the Postgraduate programmes in Telecommunications Policy and Regulation, sponsored by the Network of Telecommunications Policy and Regulation in Africa (NetTel@Africa), based in Tanzania. It is obvious therefore that the University of Jos was already getting familiar with open source software when the library adopted and deployed Dspace for its Institutional Repository (IR).

\section{University of Nigeria Nsukka.}

Eke (2011) reported that University of Nigeria, Nsukka joined this trend as it commenced the digitization of its resources in 2008. In the University of Nigeria, Nsukka, theses and dissertations are always there for researchers and students to use. It is an effort to increase the web content of the university website, as well as to preserve its intellectual content. The project is also an opportunity to develop technical infrastructure as several resources are required for the creation of digital library collections, their maintenance and provision of services. Several efforts have been made towards the full establishment of a digital library in the University of Nigeria, Nsukka, but some gaps exist in this pursuit or dream realization. Some factors may not have been put 
into consideration to enable the sustenance and growth of a digital library in the institution. However, in the case of university of Nigeria Nsukka the digitize resources are uploaded on the University websitehttp://unn.edu.ng/chart/repo

\section{Federal University of Technology Akure}

Federal University of Technology Akure started in 2011. It uses D-Space in managing the intellectual content of the repository. The sole mandate of digitizing Conference papers and presentations, Learning objects \& resources, Subject/Special Collections, Infrastructure/Administrative Records, Reference Documents, Technical reports/work papers. The above mentioned resources could be accessed through the followinghttp://dspace.futa.edu.ng:8080/jspui/

\section{Covenant University}

Covenant University is the only private university in Nigeria that owns Institutional Repository (IR). The Covenant University's institutional repositories were started in the year 2012, containing the openly accessible work of staff and students. It also includes conference proceedings and lectures. The library uses Eprint and D space, open source self archiving software. The interface is in English and it contains RSS feeds to alert users to new content. The Disciplines covers by the repository comprise Science General; Technology General; Computers and IT; Social Sciences General; Business and Economics; Law and Politics; Library and Information Science; Psychology. The resources could be accessed resources through the following links.

1. Covenant University Electronic Theses and Dissertation Repository

http://www.covenantuniversity.edu.ng/ /clr_cu/library/readonline/docsExplorer/\#

2. Covenant University Repository

http://eprints.covenantuniversity.edu.ng/

3. CU Repository

http://dspace.covenantuniversity.edu.ng/

Table 1: $\quad$ List of Nigerian Universities Registered with Opendoar

\begin{tabular}{|c|c|c|c|c|}
\hline $\mathbf{S} / \mathbf{N}$ & Universities & content & URL & Software \\
\hline 1 & $\begin{array}{l}\text { Ahmadu Bello } \\
\text { University }\end{array}$ & $\begin{array}{l}\text { Thesis, Dissertation, seminar } \\
\text { paper, Conference proceedings }\end{array}$ & http://kubanni.abu.edu.ng:8080/jspui & Dspace \\
\hline 2 & Covenant University & Articles & http://eprints.covenantuniversity.edu.ng/ & Eprint \\
\hline 3 & $\begin{array}{l}\text { Federal Uni. Tech., } \\
\text { Akure }\end{array}$ & $\begin{array}{l}\text { Articles; References; Theses } \\
\text { Learning Objects; Adm. Records, } \\
\text { Subject/Special Collections }\end{array}$ & http://dspace.futa.edu.ng:8080/jspui/ & Dspace \\
\hline 4 & $\begin{array}{l}\text { University of } \\
\text { Jos, Jos }\end{array}$ & $\begin{array}{l}\text { References; Conferences; } \\
\text { Learning Objects; Multimedia }\end{array}$ & http://dspace.unijos.edu.ng/ & Dspace \\
\hline 5 & $\begin{array}{l}\text { University of } \\
\text { Nigeria, Nsukka }\end{array}$ & Thesis and Dissertations & http://unn.edu.ng/chart/repo & $\begin{array}{c}\text { Open } \\
\text { Registry }\end{array}$ \\
\hline
\end{tabular}

Source: OpenDOAR, 2013

\section{Challenges}

Ezeani, C. N. \&Ezema I. J. (2011) from their findings reported that, the most nagging problem in the digitization project is attracting the required skills for troubleshooting of equipment such as computer systems, scanners among others. Inadequate power supply is equally a serious problem. Musa \& Musa (2012) while reporting the challenges facing Digitization project in Ahmadu Bello University equally observed that constant change of hardware and software, Copyright Issues, Technical Support and Security were among the challenges facing repositories. Eke (2011) reported similar challenges at the University of Nigeria Nssuka which includes Low Bandwidth, Technophobia, Technical Support and Security, Finance and Legal Aspects Akintunde and Anjo (2012) while reporting the problem bedeviling the project at the University of Jos stated that lack of skilled personnel to manage the repository, Lack of adequate power supply as the electricity power sector of Nigerian is poor and it really affects the servers that houses the repository. They equally observed lack of Support from the community: In terms of usage and uploading of content, where the response from the academic community so far is yet to meet with their expectations, even after several rounds of sensitization. However, it is evident that more responses have been received after each sensitization programme. So, the library will have to keep going after the user community and content providers.

\section{Prospects}

Digitization improves access to library resources. Providing access to digitized collections can help publicize the materials to other departments and peers, in other institutions around the world and demonstrate the importance of the collections. The digitization of priceless and valuable collections of the institution brings 
prestige to the whole institution as it creates visibility not only of the library's (institutions) content, but the scholars work within the university in Nigeria. Akintunde and Anjo (2012) stated that digitization holds great promise for preservation of materials, sharability of resources, and visibility of Nigerian libraries and institutions. The increase in Nigerian content on the Web will enable more meaningful and fruitful researches to be conducted through access to relevant data and literature. Nigerian libraries will also be able to communicate more professionally with colleagues in other parts of the globe. The choice and deployment of appropriate software will particularly bring contents together and provide a common platform for the exchange of knowledge in today's knowledge society. According to Bashiru (2010) today, "the global village is being described on the basis of ICT as information rich northern hemisphere and information poor southern hemisphere of which Nigeria is one. A major characteristic of an information poor society is Low-level ICT with minimum local content on the web for local and global consumption". Nigeria can only be part of this global movement by using ICT to bridge the gap and cross over.

\section{Conclusion}

Institutional Repositories plays an essential role in modern day librarianship. It creates new ways to search and access library content. Libraries in Nigeria have been making efforts to digitize their resources of their institution, despite the numerous challenges, they must set priorities concerning how records in their repositories can best be preserved and utilized to benefit the institutions and the users in this electronic age. Digital content can easily be sieved, isolated, and used without distorting the data structure. So, the old practice of librarians in 'selective dissemination of information' can be done more conveniently in a digital environment by merely touching computer keys and icons, because automatic indexing and semantic relationships are carried out in the design of different software for managing digitized content. Every effort should therefore be made to digitize and promote digitization, particularly in libraries where information is essentially harnessed for sharing to communities of users, with different information needs. Digitization Project is a step forward leading Nigerian Universities to a greater height, Strong partnership and collaboration with other related project and Donor agencies is very important. As institutional repositories offers many benefits to libraries, at this stage the beneficiaries will be the Academic libraries, although there are a lot of challenges, there is the need on the part of the library to keep abreast of constant changing technology in order to meet up with the challenges. Institutional repositories in the $21^{\text {st }}$ Century can revitalize the libraries as information providers, but only if issues of copyright, licensing, access and cost can be critically addressed to allow a wide range of libraries to adopt the concept.

\section{References}

[1]. Akintunde, S. A. \&Anjo, R. (2012) Digitizing Resources in Nigeria: An Overview Accessed December 23, 2012 Akintunde, S. A. \&Ojoade, A. B. (1995). "Coming of Age: Automation in the University of Jos Library".28p. http://dspace.unijos.edu.ng/handle/10485/857

[3]. Akintunde, Stephen A. (2010). "Blazing the trail: Institutional Repository at the University of Jos",Nigerian Libraries: Journal of the Nigerian Library Association, 43:1-19.

[4]. American Council of Learned Societies. (2006). Our Cultural Commonwealth: The report of the

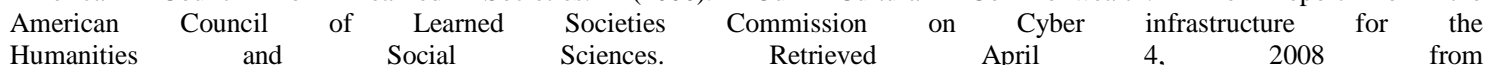
http://www.acls.org/programs/Default.aspx?id=644

[5]. Bashiru A. S. (2010) Issues and Challenges in the Creation of Institutional Repositories with Local Content: Critical Reflections. Information, Society and Justice, (3)1: 59-68.

[6]. Crow, R. (2002). The case for institutional repositories: a SPARC position paper. Retrieved

[7]. from http://www.arl.org.sparc/IR/ir.html

[8]. Cullen, R. \&Chawner, B. (2008) Institutional repositories in New Zealand: Comparing institutional strategies for digital preservation and discovery, Paper presented at Digital Discovery: Strategies \&Solutions, IATUL 2008, 20-24 April 2008, Auckland, NZ

[9]. Cullen, R. \& Nagata, H. (2008) Academic libraries in Japan. Journal of Academic Librarianship, 34 (2), 163-167.

[10]. Eke, H. N. (2011)."Digitizing resources for University of Nigeria repository: Process and $\begin{array}{lcccccc}\text { Challenges." } & \text { Webology, } & 8(1), & \text { Article } & 85 . & \text { Retrieved } & \text { from }\end{array}$ http://www.webology.org/2011/v8n1/a85.html

[11]. Ezeani, C. N. \& Ezema I. J. (2011) Digitizing Institutional Research Output of University of Nigeria, Nsukka Library Philosophy and Practice Retrieved fromhttp://unllib.unl.edu/LPP/

[12]. Fabunmi, B.A., Paris, M., \&Fabunmi, M. (2006). Digitization of library resources: Challenges And implications for policy and planning. International Journal of African \& African American Studies, Vol. V, No. 2, Jul 2006

[13]. Johnson, R. (2002). Institutional repositories: partnering with faculty to enhance scholarly communication. $\quad$ D-Lib $\quad$ Magazine, $8(11), \quad$ retrieved $\quad$ May $\quad$ 8th from http://www.dlib.org/dlib/november02/johnson/11johnson.html

[14]. Keats, D. (2004). Idlelo: First African Conference on the Digital Commons Final Report to Department of Science \& Technology South Africa, submitted by Derek Keats. http://idlelo.net/sites/default/files/Idlelo1\%20Report.pdf Accessed April 23, 2012. 
[15]. Keats, D. (2006). African Virtual Open Initiatives and Resources (AVOIR): a network for capacity

[16]. building in software engineering in Africa. United Nations Workshop for African $\begin{array}{llll}\text { Parliamentary information } & \text { systems. } & \text { http://www.parliaments.info/downloads/14\%20 } & \text { Derek }\end{array}$ \%20Keats\%20\%20African\%20Virtual\%20Open\%20Initiatives\%20and\%20Resources\%20\%28

AVOIR \%29\%20a\%20network\%20for\%20capacity\%20building\%20in\%20software\%20engin eering\%20in\%20Africa. pdf Accessed April 23, 2012.

[17]. Lynch, C. (2003). Institutional Repositories: Essential Infrastructure for Scholarship in the Digital Age. ARL, 226, Retrieved April 13, 2008 from http://www.arl.org/bm doc/br226ir.pdf

[18]. Mohammed, Z. (2009). Towards establishment and management of institutional digital repository. Libraries Create Future: Building on Cultural Heritage. Paper presented at the $47^{\text {th }}$ Annual National Conference \& AGM of Nigerian Library Association, at Ibadan, 26 - 31, 99108

[19]. Musoke, M. (2008). Strategies for addressing the university library users' changing needs and practices in Sub-Saharan Africa, Journal of Academic Librarianship, 34(6) [in press].

[20]. Pinfield, S., Gardner, M., \&MacColl, J. (2002). Setting up an institutional E-print archive. Ariadne, 31.

[21]. SearchEnterpriseLinux (2008). Free and open source software (FOSS) or free/libre open sourcesoftware $\quad$ (FLOSS). http://searchenterpriselinux.techtarget.com/definition/Free-andopensource-software-FOSS Accessed April 23, 2012.

[22]. Thata, M.B.(2007). Building a digital library at the University of Zimbabwe: A celebration of team work and collaboration. 